\title{
Effects of Three Nitrification Inhibitors on the Nitrogen Conversion in Purple Soil and Its Effect on the Nitrogen Uptake of Citrus Seedlings
}

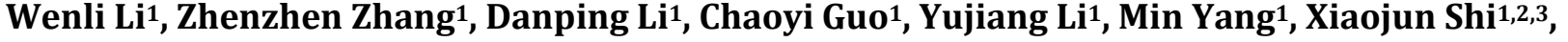 \\ Yueqiang Zhang1,2,3* \\ ${ }^{1}$ College of Resources and Environment, Southwest University, Chongqing, China \\ ${ }^{2}$ Academy of Agricultural Sciences, Southwest University, Chongqing, China \\ ${ }^{3}$ National Monitoring Station of Soil Fertility and Fertilizer Efficiency on Purple Soils, Chongqing, China \\ Email: *zhangyq82@swu.edu.cn
}

How to cite this paper: Li, W.L., Zhang, Z.Z., Li, D.P., Guo, C.Y., Li, Y.J., Yang, M., Shi, X.J. and Zhang, Y.Q. (2018) Effects of Three Nitrification Inhibitors on the Nitrogen Conversion in Purple Soil and Its Effect on the Nitrogen Uptake of Citrus Seedlings. Agricultural Sciences, 9, 655-669. https://doi.org/10.4236/as.2018.96045

Received: May 9, 2018

Accepted: June 17, 2018

Published: June 20, 2018

Copyright $\odot 2018$ by authors and Scientific Research Publishing Inc. This work is licensed under the Creative Commons Attribution International License (CC BY 4.0).

http://creativecommons.org/licenses/by/4.0/

(c) (i) Open Access

\begin{abstract}
Experiments were carried out to study the effects of nitrification inhibitors (NI) on the transformation of soil nitrogen $(\mathrm{N})$ in purple soil and the effects on the $\mathrm{N}$ accumulation in different organs of citrus seedlings. In incubation and pot experiments, the rate of nitrification inhibitors 2-chloro-6-trichloromethyl pyridine (Nitrapyrin), 3,4-dimethylpyrazole phosphate (DMPP) and dicyandiamide (DCD) was $2.4 \%, 1.0 \%$ and $5.0 \%$ of $\mathrm{N}$ rate, respectively. The trend of different nitrification inhibitors on ammonium nitrogen $\left(\mathrm{NH}_{4}^{+}-\mathrm{N}\right)$, nitrate nitrogen $\left(\mathrm{NO}_{3}^{-}-\mathrm{N}\right)$ content and $\mathrm{pH}$ was compared in incubation experiment; and the effect of different $\mathrm{NI}$ on the dry matter quality, $\mathrm{N}$ uptake of citrus seedling was studied in pot experiment. The results showed that NI could significantly inhibit soil nitrification in the early culture period ( $\mathrm{p}<$ 0.05). The inhibitory degree of NI on nitrification showed the strong tendency at the beginning and then decreased. During the whole experiment, nitrification inhibition rates were $4.4 \%-48.5 \%$ (En), 6.7\% - 9.8\% (DMPP) and 5.1\% $97.2 \%$ (DCD), respectively. Compared with the control, the application of NI increased the plant height and dry matter accumulation of potted citrus seedlings by $7.6 \%-8.6 \%$ and $1.0 \%-3.8 \%$, respectively. And application of NI also increased the absorption of $\mathrm{N}$ by citrus roots and leaves by $9.0 \%-17.9 \%$ and $0.6 \%-7.2 \%$, respectively. Overall, all the three nitrification inhibitors could significantly delay the soil nitrification process in purple soil, with the order of inhibition ability of DCD > DMPP > En (calculated as nitrogen application rate). Application of NI increased the height and dry matter accu-
\end{abstract}


mulation, $\mathrm{N}$ accumulation of citrus seedling grown in pot experiment. Thus, application of NI would be helpful for improving $\mathrm{N}$ use efficiency in purple soil which is one of major soil types for citrus production in China.

\section{Keywords}

Citrus, Nitrification Inhibitors, Soil, Nitrogen

\section{Introduction}

China is the world with the largest citrus cultivation area and the largest production of citrus, accounting for $31 \%$ and $25 \%$ of the world respectively [1], which plays an important role in regulating the production and trade of citrus in the world. Chongqing is one of the major areas of citrus cultivation in China, and citrus has become one of the main ways of local farmers' income. Citrus is a typical perennial evergreen fruit tree. Its growth and development need to consume large amounts of a variety of nutrition elements. Fertilization is the important factors influencing the growth, yield and quality of citrus [2]. Nitrogen is the essential nutrient elements in the process of citrus growth. $\mathrm{NH}_{4}^{+}-\mathrm{N}$ and $\mathrm{NO}_{3}^{-}-\mathrm{N}$ are the main source of nitrogen that can be utilized by citrus [3]. In the process of production, $\mathrm{NO}_{3}^{-}-\mathrm{N}$ in the soil is easily lost with water, causing the low utilization rate of fertilizer, such problems as environmental pollution [4]. The main producing areas of citrus in China are mainly located in the southern hilly area. Citrus orchards mostly have steep slopes, poor soil, and complex terrain, soil erosion and other problems often occur [5]. The addition of nitrification inhibitors to fertilizers reduces the rate of conversion of ammonium and amide nitrogen to nitrate nitrogen and reduces the migration of nitrate nitrogen into the water environment, and has been considered as one of the important measures to increase nitrogen use efficiency [6]. Predecessors' Research Progress: Many countries have applied nitrification inhibitors to actual production, and nitrification inhibitors have played a very good role in reducing $\mathrm{NO}_{3}^{-}-\mathrm{N}$ leaching, $\mathrm{NO}_{2}^{-}-\mathrm{N}$ emissions, and increasing nitrogen use efficiency [7]. There are many kinds of nitrification inhibitors, mainly cyanamides, nitrogen-containing heterocyclic compounds, sulfur-containing compounds, hydrocarbons and their derivatives, among which the commonly used in agricultural production includes dicyandiamide (DCD), 3,4-dimethylpyrazole phosphate (DMPP), 2-chloro-6-trichloromethyl pyridine (Nitrapyrin) and acetylene $\left(\mathrm{C}_{2} \mathrm{H}_{2}\right)$ [6]. Nitrification inhibitors DMPP, DCD can inhibit soil ammonia oxidation, significantly increase the concentration of ammonium in soil, reduce the concentration of nitrate nitrogen, and slow down the acidification rate of the soil [8]. Indoor simulation experiments showed that nitrification inhibitors (DMPP, En and DCD) can inhibit the conversion of ammonium nitrogen to nitrate nitrogen [9]. At the same time, field trials also showed that nitrification inhibitors can 
improve the quality of fragrant pears and ash jujube fruits [10] [11]. DMPP compound fertilizer can significantly improve the yield and quality of watermelon and cucumber [12]. Nitrification inhibitors can also slow down the acidification rate of the soil by weakening the nitrification of the soil, thereby weakening the acidification caused by $\mathrm{H}^{+}$during the nitrification process and making the $\mathrm{pH}$ increase [13] [14]. The nitrification inhibitor DMPP can significantly increase nitrogen accumulation and dry matter quality in leaves, stems, and roots of plants [15]. In recent years, nitrification inhibitors have been widely used in many crops such as field crops. Studies have shown that nitrification inhibitors can not only increase the yield of crops, but also reduce the leaf green and nitrate content of leafy vegetables, and increase the starch content of sugar beets and potatoes [16]. However, at present domestic nitrification inhibitors are mainly studied in food, economy, and vegetable crops. Relative to foreign countries, there are few studies on nitrification inhibitors in fruit trees in China [11]. Research entry point: In China, the main citrus production areas are mainly located in the southern hilly areas. Citrus orchards mostly have steep slopes, poor soil, complex terrain, and soil erosion problems often occur [5]. Most citrus cultivation areas in Chongqing are purple soil. The soil layer is thin, the nutrients are poor, and they are easily lost with water. The ability of the soil to retain water and fertility is poor. Therefore, the transformation process of nitrogen in purple soil is regulated, which promotes its effective utilization, and reduces nitrogen loss [17] [18] [19]. It is of great significance for the efficient management and environmental protection of nitrogen fertilizer. Problems to be solved: This paper aims to understand the effects of nitrification inhibitors on nitrogen forms and transformation of purple soil and to understand the effects of nitrification inhibitors on nutrient accumulation in different organs of citrus seedlings through indoor simulation experiments and pot experiments.

\section{Materials and Methods}

\subsection{Laboratory Culture Experiment}

Soil samples were collected from the purple soil test base of southwest university in Beibei district, Chongqing. The soil sample is dried, and the impurities are removed and then polished to a $2 \mathrm{~mm}$ sieves. The basic physical and chemical properties of the tested soil as: $\mathrm{pH} 7.49$, organic matter $9.90 \mathrm{~g} \cdot \mathrm{kg}^{-1}$, total nitrogen content $0.67 \mathrm{~g} \cdot \mathrm{kg}^{-1}$, total phosphorus content $0.74 \mathrm{~g} \cdot \mathrm{kg}^{-1}$ and total potassium content $21.41 \mathrm{~g} \cdot \mathrm{kg}^{-1}$, available nitrogen content $68.90 \mathrm{mg} \cdot \mathrm{kg}^{-1}$, available $\mathrm{p}$ content $19.89 \mathrm{mg} \cdot \mathrm{kg}^{-1}$ and available $\mathrm{k}$ content $96.50 \mathrm{mg} \cdot \mathrm{kg}^{-1}$. The test reagents included urea, potassium dihydrogen phosphate and nitrification inhibitors are analytical reagents. Nitrification inhibitors select the commonly used 2-chloro6-trichloromethyl pyridine (Nitrapyrin), 3,4-dimethylpyrazole phosphate (DMPP) and dicyandiamide (DCD).

The experiment consisted of four treatments: the three commonly used nitri- 
fication inhibitors, Nitrapyrin (En), DMPP and DCD, plus a single urea treatment as the control CK, and each has 4 repetitions. Nitrapyrin, DMPP and DCD were used in $2.4 \%, 1 \%$ and $5 \%$ of $\mathrm{N}$ rate respectively (the same amount of nitrogen fertilizer was used in this experiment). The method was: the same treatment was taken with $9.6 \mathrm{~kg}$ of air dried soil sample, mixed with urea $\left(0.2 \mathrm{~g} \cdot \mathrm{kg}^{-1}\right)$. The soil moisture content was $70 \%$ of the maximum amount of water in the field (WHC), and the dry soil moisture content was $4 \%$. Dissolve the nitrification inhibitor in the added water and spray it completely in the soil. The $300 \mathrm{~g}$ mixed soil samples were respectively put into $500 \mathrm{ml}$ plastic bottles, sealed and perforated to ensure ventilation, each treatment had 32 bottles. The soil sample was played in $25^{\circ} \mathrm{C}$ (in constant temperature and humidity incubator) training for 80 days. During the training period, the loss of water in the training process was supplemented by weighing method every 7 days, and in 2, 4, 18, 35, 50, 65, 80, 65 days, each treatment was taken out of one group ( 4 bottles for each treatment), respectively determined the content of ammonium nitrogen and nitrate nitrogen in soil, and determined the soil $\mathrm{pH}$ value.

\subsection{Pot Experiment}

The soil and nitrification inhibitors were the same as the indoor culture tests. Test fertilizer: nitrogen fertilizer is urea (46.4\%); phosphate fertilizer is calcium superphosphate $(12 \%)$; potassium fertilizer is potassium sulfate $(51 \%)$; organic fertilizer contains nitrogen (water content 44\%). Citrus seedling is an annual mandarin (Citrus mandarinus), rootstock is Fructus aurantii. Four treatments were set up in the experiment, they were: 1) CK (N), 2) $\mathrm{N}+$ En (normal En dosage), 3) $\mathrm{N}+\mathrm{DMPP}$, 4) $\mathrm{N}+\mathrm{DCD}$. There were 5 repeats in each treatment, random block arrangement.

The experiment was conducted in the pot planting net room of National Purple Soil Fertility and Fertilizer Efficiency Monitoring Station of Southwest University. The air dry soil in ceramic pot was $10 \mathrm{~kg}$. In one kilogram of soil, the amount of nitrogen fertilizer was $0.2 \mathrm{~g}$, and the amount of phosphorus and potassium fertilizer was $0.1 \mathrm{~g}$. According to the recommended amount of nitrification inhibitor, the amount of DMPP is $1 \%$ of the amount of nitrogen fertilizer, the amount of DCD is $5 \%$ of the amount of nitrogen fertilizer, and the amount of En is $2.4 \%$ of the amount of nitrogen fertilizer. The specific dosage is shown in Table 1. All fertilizers are used as base fertilizers at one time. Soil, fertilizer

Table 1. The rate of nitrification inhibitors and fertilizers with different treatments.

\begin{tabular}{cccccc}
\hline Treatment & $\begin{array}{c}\text { Loading quantity of soil } \\
\left(\mathrm{kg} \cdot \mathrm{pot}^{-1}\right.\end{array}$ & $\begin{array}{c}\text { Nitrification inhibitor } \\
\left(\mathrm{mg} \cdot \mathrm{pot}^{-1}\right)\end{array}$ & $\begin{array}{c}\mathrm{N} \\
\left(\mathrm{g} \cdot \mathrm{pot}^{-1}\right)\end{array}$ & $\begin{array}{c}\mathrm{P}_{2} \mathrm{O}_{5} \\
\left(\mathrm{~g} \cdot \mathrm{pot}^{-1}\right)\end{array}$ & $\begin{array}{c}\mathrm{K}_{2} \mathrm{O} \\
\left(\mathrm{g} \cdot \mathrm{pot}^{-1}\right)\end{array}$ \\
\hline $\mathrm{CK}(\mathrm{N})$ & 10 & 0 & 2 & 1 & 1 \\
$\mathrm{~N}+$ En & 10 & 24 & 2 & 1 & 1 \\
$\mathrm{~N}+$ DMPP & 10 & 20 & 2 & 1 & 1 \\
$\mathrm{~N}+$ DCD & 10 & 100 & 2 & 1 & 1 \\
\hline
\end{tabular}


and nitrification inhibitor were mixed in a pot. After 2 - 3 days of culture, citrus seedlings were transplanted. During transplanting, the growth of citrus seedlings was consistent and the seedlings were watered regularly. The planting time of citrus pot is from March to October.

\subsection{Plant and Soil Measurement}

The mass concentration of ammonium nitrogen and nitrate nitrogen in soil was determined by flow analyzer, and the $\mathrm{pH}$ of soil was measured by $\mathrm{pH}$ meter, the citrus seedlings were divided into three parts: root, stem and leaf after harvest, the surface soil was washed away, dried, and the dry matter was measured by weighing. After the plant samples were pulverized, the contents of nitrogen, phosphorus and potassium were determined by distillation, vanadium molybdenum yellow colorimetry, flame photometry, and the contents of ammonium nitrogen, nitrate nitrogen, total nitrogen and alkali-hydrolyzed nitrogen were also determined. Other soil physicochemical properties refer to routine analysis methods [20].

\subsection{Data Analysis}

Excel and SigmaPlot data processing software are used to make charts and graphs, and SPSS 16.0 statistical analysis software is used to analyze the data. Each data is the average value of repetition

$$
\begin{gathered}
\text { Apparent nitrification rate of soil }=\frac{\mathrm{NO}_{3}^{-}-\mathrm{N}+\mathrm{NO}_{2}^{-}-\mathrm{N}+\mathrm{NO}_{3}^{-}-\mathrm{N}}{\mathrm{NO}_{3}^{-}-\mathrm{N}} * 100 \\
\text { Nitrification inhibition rate }=\frac{A-B}{A} * 100
\end{gathered}
$$

$\mathrm{A}$ is the difference of nitrate content before and after incubation without nitrification inhibitor treatment $\left(\mathrm{mg}^{\mathrm{kg}} \mathrm{kg}^{-1}\right), \mathrm{B}$ is the difference of nitrate nitrogen content before and after treatment $\left(\mathrm{mg} \cdot \mathrm{kg}^{-1}\right)$.

\section{Results}

\subsection{Effects of Nitrification Inhibitors on Nitrogen Forms and Transformation in Soil (Incubation Experiment)}

\subsubsection{Effects of Different Nitrification Inhibitors on Soil Nitrogen Conversion}

With the increase of culture time, the content of $\mathrm{NH}_{4}^{+}-\mathrm{N}$ in soil increased first and then decreased (Figure 1). On the second day of culture, the $\mathrm{NH}_{4}^{+}-\mathrm{N}$ content of all treatments reached its peak and then began to decrease. The $\mathrm{NH}_{4}^{+}-\mathrm{N}$ content of CK treatment decreased the most rapidly, which decreased from $118.7 \mathrm{mg} \cdot \mathrm{kg}^{-1}$ on the $2^{\text {nd }}$ days to $5.9 \mathrm{mg} \cdot \mathrm{kg}^{-1}$ on the 35 th day, with a decrease of $95.0 \%$. However, the content of $\mathrm{NH}_{4}^{+}-\mathrm{N}$ treated by En decreased by $80.7 \%$, DMPP and DCD treatment decreased by $62.3 \%$ and $54.5 \%$ respectively, and the decrease of nitrification inhibitor treatment was significantly lower than that of CK treatment $(\mathrm{p}<0.01)$. 

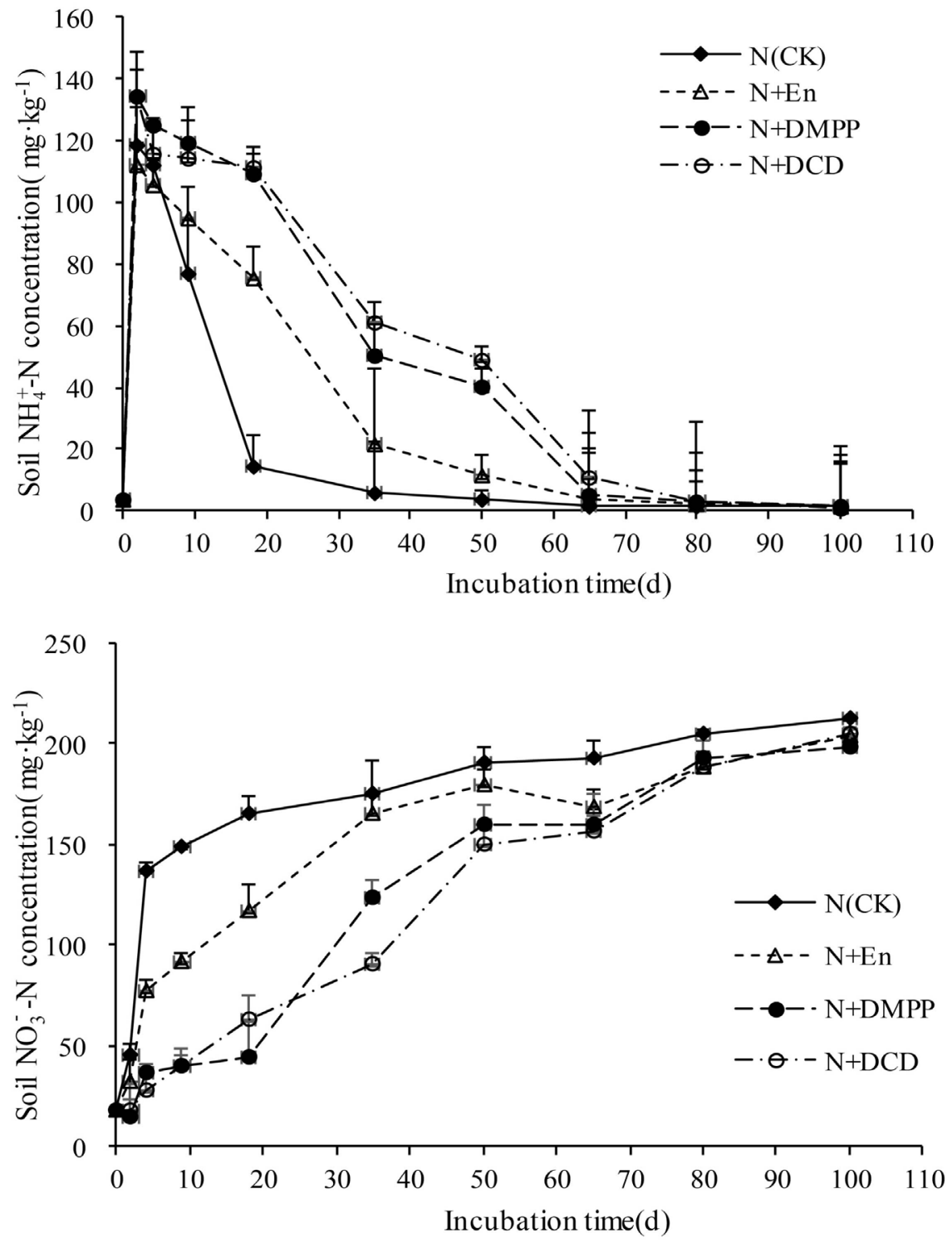

Figure 1. Concentration of $\mathrm{NH}_{4}^{+}-\mathrm{N}$ and $\mathrm{NO}_{3}^{-}-\mathrm{N}$ in purple soil with different nitrification inhibitors. Note: En, 2-Chloro-6-trichloromethyl pyridine; DMPP, 3, 4-Dimethylpyrazole Phosphate; DCD, dicyandiamide.

Contrary to the change trend of $\mathrm{NH}_{4}^{+}-\mathrm{N}$ content, soil $\mathrm{NO}_{3}^{-}-\mathrm{N}$ content gradually increased with the increase of culture time, and the change trend of each treatment was similar (Figure 1). The $\mathrm{NO}_{3}^{-}-\mathrm{N}$ content of $\mathrm{CK}$ increased rapidly at the beginning of culture and reached $165.2 \mathrm{mg} \cdot \mathrm{kg}^{-1}$ on the 18 th day. After that, the content of $\mathrm{NO}_{3}^{-}-\mathrm{N}$ increased slowly. The content of $\mathrm{NO}_{3}^{-}-\mathrm{N}$ in soil treated with En, DMPP and DCD were 116.5, 44.5 and $63.5 \mathrm{mg} \cdot \mathrm{kg}^{-1}$ respectively on the 18th day, which was significantly lower than that of $\mathrm{CK}$ treatment $(\mathrm{p}<0.01)$. During the whole culture period, the content of $\mathrm{NO}_{3}^{-}-\mathrm{N}$ in soil treated by DCD was basically at the lowest level, and the inhibition effect was better than that of DMPP and En treatment, followed by DMPP treatment. 


\subsubsection{Effects of Different Nitrification Inhibitors on Soil pH Transformation}

The soil $\mathrm{pH}$ increased first and then decreased with the increase of culture time (Figure 2), which is consistent with the change trend of $\mathrm{NH}_{4}^{+}-\mathrm{N}$ content in Figure 1. The soil $\mathrm{pH}$ of each treatment increased to the highest level on the 2 nd day after culture, which was 8.0 (CK), 8.2 (En), 8.3 (DMPP) and 8.3(DCD) respectively, and then began to decrease in different amplitude. The $\mathrm{pH}$ of CK treatment decreased from 7.5 at the initial stage to 6.2 on the 35th day, the decrease was 1.3, and then the $\mathrm{pH}$ decreased slowly $(19-100 \mathrm{~d})$, and the $\mathrm{pH}$ value was 6.1 at the end of culture. From the second day of culture, the $\mathrm{pH}$ value of soil treated with En, DMPP and DCD nitrification inhibitor was significantly higher than that of CK treatment $(\mathrm{p}<0.01)$, but there was no significant difference between En and DMPP treatment. Therefore, the addition of nitrification inhibitors to the soil can significantly slow down the soil acidification rate.

Statistical analysis showed (Table 2) under nitrification inhibitor treatment, soil $\mathrm{NH}_{4}^{+}-\mathrm{N}$ concentration was negatively correlated with $\mathrm{NO}_{3}^{-}-\mathrm{N}$ concentration. $\mathrm{NH}_{4}^{+}-\mathrm{N}$ concentration was significant positively correlated with $\mathrm{pH}$ value $(\mathrm{p}<0.05)$ and $\mathrm{NO}_{3}^{-}-\mathrm{N}$ concentration was significant negatively correlated with $\mathrm{pH}$ value $(\mathrm{p}<0.01)$.

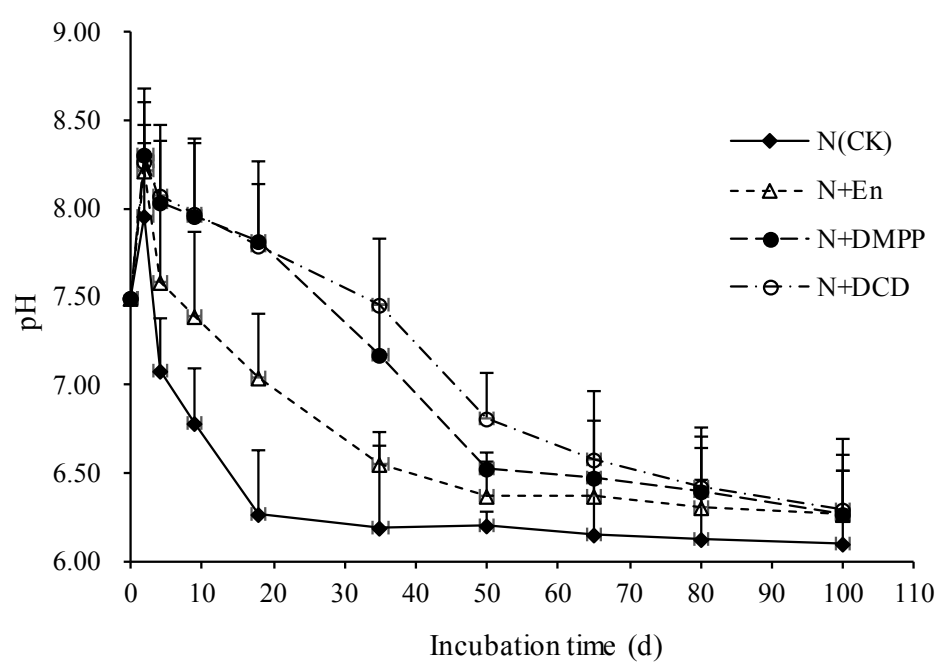

Figure 2. Soil $\mathrm{pH}$ in purple soil with different nitrification inhibitors.

Table 2. Correlation between parameters of soil treated with different nitrification inhibitors.

\begin{tabular}{cccc}
\hline Treatments & $\mathrm{NH}_{4}^{+}-\mathrm{N}$ vs. $\mathrm{NO}_{3}^{-}-\mathrm{N}$ & $\mathrm{NH}_{4}^{+}-\mathrm{N}$ vs. $\mathrm{pH}$ & $\mathrm{NO}_{3}^{-}-\mathrm{N}$ vs. $\mathrm{pH}$ \\
\hline $\mathrm{CK}$ & -0.458 & $0.718^{*}$ & $-0.936^{* *}$ \\
$\mathrm{~N}+\mathrm{En}$ & -0.606 & $0.805^{* *}$ & $-0.944^{* *}$ \\
$\mathrm{~N}+\mathrm{DMPP}$ & $-0.727^{*}$ & $0.879^{* *}$ & $-0.955^{* *}$ \\
$\mathrm{~N}+\mathrm{DCD}$ & $-0.703^{*}$ & $0.881^{* *}$ & $-0.952^{* *}$ \\
\hline
\end{tabular}

Note: Correlation is significant at the $95 \%$ level $(n=30)$. 


\subsubsection{Effect of Different Nitrification Inhibitors on Soil Apparent Nitrification Rate}

The intensity of $\mathrm{NH}_{4}^{+}-\mathrm{N}$ nitrification in soil is generally expressed by the apparent nitration rate. Overall, with the extension of culture time, the apparent nitrification rates of different treatments in purple soil showed a gradually increasing trend (Table 3). In the first 4 days of cultivation, the apparent nitrification rate of soil treated with CK was between $27.3 \%$ and $54.6 \%$, and then rapidly increased to $91.8 \%$, reaching $99.1 \%$ at the end of cultivation. The addition of nitrification inhibitors significantly inhibited the nitrification of ammonium nitrogen. En, DMPP and DCD treatments were all lower than CK treatment during the first 80 days of culture. The apparent nitrification rates of DMPP and DCD were all at low levels during the first 50 days of culture, ranging from $9.8 \%$ to $79.7 \%$ and $11.7 \%$ to $73.5 \%$, respectively, which were significantly lower than En treatment $(\mathrm{p}<0.05)$. There was no significant difference between DMPP and DCD.

\subsubsection{Effects of Different Nitrification Inhibitors on the Rate of Soil Nitrification Inhibitors}

Nitrification inhibition rate can be used to characterize the inhibition of nitrification inhibitors. The inhibition degree of nitrification by En, DMPP and DCD showed the tendency of strong first and then weak (Table 4), and the nitrification inhibition rate of nitrogen with En application treatment was between $33.1 \%$ and $48.5 \%$ within 18 days incubation. At the 50th day, the inhibition rate rapidly decreased to $6.0 \%$, and the inhibition rate of nitrification of nitrogen by En was $4.40 \%$ at the end of culture. During the 18 days incubation, the inhibition

Table 3. Apparent nitrification rate of different treatments in purple soil (\%).

\begin{tabular}{ccccccccc}
\hline & \multicolumn{7}{c}{ Apparent nitrification rate \% } \\
\cline { 2 - 8 } Treatments & 2 & 4 & 18 & 35 & 50 & 65 & 80 & 100 \\
\hline $\mathrm{N}(\mathrm{CK})$ & $27.3 \mathrm{a}$ & $54.6 \mathrm{a}$ & $91.8 \mathrm{a}$ & $96.6 \mathrm{a}$ & $97.9 \mathrm{a}$ & $99.2 \mathrm{a}$ & $99.2 \mathrm{a}$ & $99.1 \mathrm{a}$ \\
$\mathrm{N}+\mathrm{En}$ & $21.9 \mathrm{a}$ & $41.8 \mathrm{~b}$ & $60.5 \mathrm{~b}$ & $88.4 \mathrm{~b}$ & $93.9 \mathrm{a}$ & $97.7 \mathrm{a}$ & $98.8 \mathrm{a}$ & $99.1 \mathrm{a}$ \\
$\mathrm{N}+\mathrm{DMPP}$ & $9.8 \mathrm{~b}$ & $22.5 \mathrm{c}$ & $28.8 \mathrm{c}$ & $70.8 \mathrm{c}$ & $79.7 \mathrm{~b}$ & $96.9 \mathrm{a}$ & $98.5 \mathrm{a}$ & $99.3 \mathrm{a}$ \\
$\mathrm{N}+$ DCD & $11.7 \mathrm{~b}$ & $18.9 \mathrm{c}$ & $36.3 \mathrm{~d}$ & $59.7 \mathrm{~d}$ & $73.5 \mathrm{~b}$ & $93.2 \mathrm{~b}$ & $98.4 \mathrm{a}$ & $99.5 \mathrm{a}$ \\
\hline
\end{tabular}

Note: En,2-chloro-6-trichloromethyl pyridine (Nitrapyrin), DMPP,3,4-dimethylpyrazole phosphate, DCD, dicyandiamide. Different lowercase letters in the same column indicate significant difference at $\mathrm{p}<0.05$ level. The same below.

Table 4. Nitrification inhibition rate (\%) of DMPP, DCD, and En in purple soil.

\begin{tabular}{ccccccccc}
\hline & \multicolumn{7}{c}{ Nitrification inhibition rate (\%) } \\
\cline { 2 - 8 } Treatments & 2 & 4 & 18 & 35 & 50 & 65 & 80 & 100 \\
\hline N + En & $48.5 \mathrm{a}$ & $50.1 \mathrm{a}$ & $33.1 \mathrm{a}$ & $6.2 \mathrm{a}$ & $6.0 \mathrm{a}$ & $13.5 \mathrm{a}$ & $8.8 \mathrm{a}$ & $4.4 \mathrm{a}$ \\
$\mathrm{N}+\mathrm{DMPP}$ & $95.8 \mathrm{~b}$ & $84.0 \mathrm{~b}$ & $81.9 \mathrm{~b}$ & $32.9 \mathrm{~b}$ & $17.5 \mathrm{~b}$ & $18.7 \mathrm{a}$ & $6.4 \mathrm{a}$ & $6.7 \mathrm{ab}$ \\
$\mathrm{N}+$ DCD & $97.2 \mathrm{~b}$ & $92.0 \mathrm{~b}$ & $69.0 \mathrm{c}$ & $53.7 \mathrm{c}$ & $23.1 \mathrm{c}$ & $20.7 \mathrm{a}$ & $8.6 \mathrm{a}$ & $5.1 \mathrm{ab}$ \\
\hline
\end{tabular}


rate of DCD and DMPP treatment was $81.9 \%$ - 95.8\% and 69.0\% - 97.2\%, respectively. After that, the nitrification inhibition rate of DMPP was reduced rapidly and DCD treatment was reduced slowly. In the first 65 days of culture, the inhibition rate of nitration by DCD and DMPP treatment was significantly higher than that of En treatment $(p<0.05)$. After that, the difference in nitrification inhibition rate of each treatment was smaller. In the treatment of three nitrification inhibitors, the treatment rate of nitrification inhibitors by DCD was the highest, followed by DMPP treatment. The results were consistent with the previous text.

\subsection{Effects of Nitrification Inhibitors on Nutrients Content of Soil and Citrus Seedlings (Pot Experiment)}

\subsubsection{Effects of Nitrification Inhibitors on Plant Height and Dry Matter Accumulation of Citrus Seedlings}

The effects of nitrification inhibitors on plant height and dry matter accumulation were shown in Figure 3. The application of nitrification inhibition DCD treatment significantly increased the citrus plant height, which increased by $11.7 \%$ compared with the control treatment. Other nitrification inhibitors had a certain effect on the growth of citrus plant height, and the increase was between $7.6 \%$ and $8.6 \%$, but the difference was not significant $(\mathrm{p}<0.05)$. The treatment of nitrification inhibitors also promoted the dry matter accumulation of citrus, but the difference did not reach the significant level $(\mathrm{p}<0.05)$.

\subsubsection{Effects of Nitrification Inhibitors on Nutrient Uptake of Citrus Seedlings}

Compared with the control, the application of nitrification inhibition had a certain effect on the content of nitrogen in citrus roots and leaves, and there was no significant difference in the nitrogen content of the old stem and the new stem of citrus (Figure 4). Nitrification inhibitor DCD significantly increased the uptake of nitrogen by citrus roots. The amount of nitrogen uptake was increased by $17.9 \%$ compared with the control. The amount of nitrogen uptake in other treated roots was $9.0 \%-13.6 \%$ higher than that of the control treatment, and the difference was not significant. The nitrification inhibitor DMPP significantly
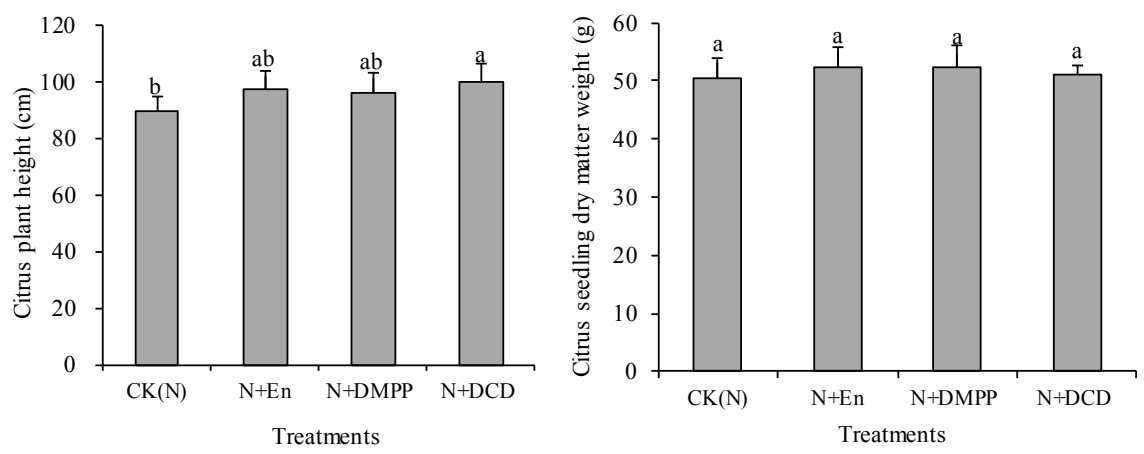

Figure 3. Effect of nitrification inhibitors on plant height and dry matter accumulation of citrus. 

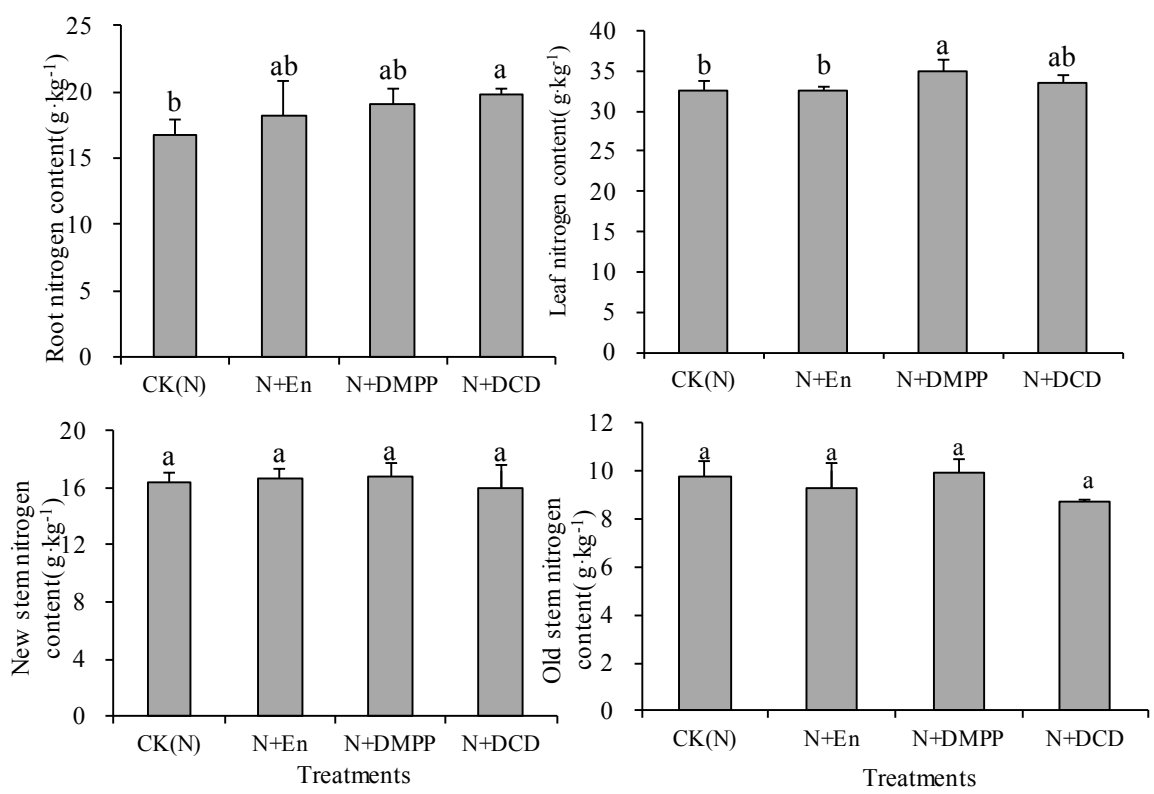

Figure 4. Effect of nitrification inhibitors on nitrogen accumulation of citrus parts.

increased the uptake of nitrogen by citrus leaves, the amount of nitrogen uptake was increased by $7.6 \%$ compared to the control. Other nitrification inhibitors increased the nitrogen content of citrus leaves, but the difference was not significant.

Compared with urea only, application of nitrification inhibitors could increase the amount of nitrogen accumulation in citrus plants (Figure 5), but there was no significant difference among treatments $(p<0.05)$. Among them, DMPP treatment had the highest accumulation of nitrogen in citrus plants, nitrogen accumulation increased by $11.14 \%$ compared with the control, followed by En treatment, it increased by $6.18 \%$.

The effects of nitrification inhibitors on the accumulation of phosphorus and potassium in various parts of potted citrus are shown in Table 5. Compared with the control, the application of nitrification inhibition did not significantly increase the amount of phosphorus uptake and potassium uptake in citrus leaves, old stems, new stems, and roots. The DCD treatment had the highest phosphorus uptake and potassium uptake in all parts of the citrus.

\subsubsection{Effects of Nitrification Inhibitors on Soil Nitrogen}

The three nitrification inhibitors increased soil total nitrogen, alkali-hydrolyzable nitrogen, ammonium nitrogen, and nitrate nitrogen in different degrees, and improved soil fertility. Compared with the control, the nitrification inhibitors En and DCD significantly increased soil total nitrogen and alkali-hydrolyzable nitrogen, and the total nitrogen and alkaline nitrogen increased by $3.9 \%-4.0 \%$ and $6.0 \%-7.3 \%$, respectively. DMPP had no significant increase in soil total nitrogen and alkaline dissolved nitrogen content. The nitrification inhibitor En significantly increased the content of ammonium nitrogen and nitrate in the soil, 
Table 5. Effect of nitrification inhibitors on phosphate-potassium accumulation of citrus parts.

\begin{tabular}{|c|c|c|c|c|c|c|c|c|}
\hline \multirow[b]{2}{*}{ Treatments } & \multicolumn{2}{|c|}{ Leaf $\left(\mathrm{g} \cdot \mathrm{kg}^{-1}\right)$} & \multicolumn{2}{|c|}{ New stem $\left(\mathrm{g} \cdot \mathrm{kg}^{-1}\right)$} & \multicolumn{2}{|c|}{ Old stem $\left(\mathrm{g} \cdot \mathrm{kg}^{-1}\right)$} & \multicolumn{2}{|c|}{ Root $\left(\mathrm{g} \cdot \mathrm{kg}^{-1}\right)$} \\
\hline & $\begin{array}{c}\text { Total } \\
\text { phosphorus }\end{array}$ & $\begin{array}{c}\text { Total } \\
\text { potassium }\end{array}$ & $\begin{array}{c}\text { Total } \\
\text { phosphorus }\end{array}$ & $\begin{array}{c}\text { Total } \\
\text { potassium }\end{array}$ & $\begin{array}{c}\text { Total } \\
\text { phosphorus }\end{array}$ & $\begin{array}{c}\text { Total } \\
\text { potassium }\end{array}$ & $\begin{array}{c}\text { Total } \\
\text { phosphorus }\end{array}$ & $\begin{array}{c}\text { Total } \\
\text { potassium }\end{array}$ \\
\hline CK $(\mathrm{N})$ & $1.5 \mathrm{a}$ & $10.3 \mathrm{a}$ & $1.3 \mathrm{ab}$ & $6.4 \mathrm{ab}$ & $0.60 \mathrm{a}$ & $3.5 \mathrm{a}$ & $1.0 \mathrm{a}$ & $14.2 \mathrm{a}$ \\
\hline$N+E n$ & $1.8 \mathrm{a}$ & $10.5 \mathrm{a}$ & $1.1 \mathrm{~b}$ & $6.3 \mathrm{~b}$ & $0.50 \mathrm{a}$ & $3.6 \mathrm{a}$ & $0.9 \mathrm{a}$ & $14.1 \mathrm{a}$ \\
\hline $\mathrm{N}+\mathrm{DMPP}$ & $1.5 \mathrm{a}$ & $10.4 \mathrm{a}$ & $1.4 \mathrm{a}$ & $6.9 \mathrm{ab}$ & $0.6 \mathrm{a}$ & $3.8 \mathrm{a}$ & $1.0 \mathrm{a}$ & $14.5 \mathrm{a}$ \\
\hline $\mathrm{N}+\mathrm{DCD}$ & $1.6 \mathrm{a}$ & $10.7 \mathrm{a}$ & $1.4 \mathrm{a}$ & $7.8 \mathrm{a}$ & $0.6 \mathrm{a}$ & $4.2 \mathrm{a}$ & $1.1 \mathrm{a}$ & $15.8 \mathrm{a}$ \\
\hline
\end{tabular}

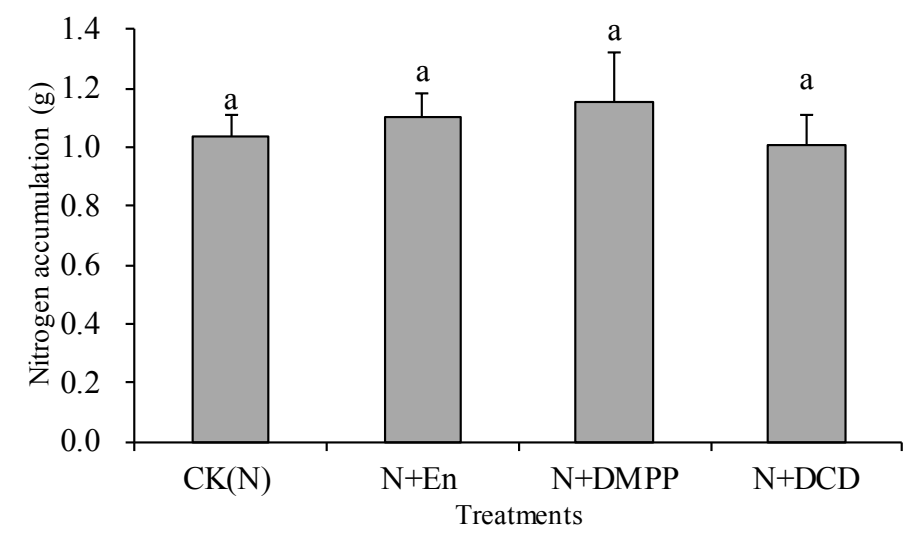

Figure 5. Effect of nitrification inhibitors on nitrogen accumulation of citrus plant.

which was increased by $18.7 \%$ and $17.6 \%$ respectively compared with the control. Other nitrification inhibitors increased the content of ammonium nitrogen and nitrate in the soil, but the difference was not significant $(\mathrm{p}<0.05)$.

\section{Discussion}

\subsection{Effects of Nitrification Inhibitors on Soil Nitrogen Conversion}

In the cultivation process, the conversion of urea was suppressed due to the addition of nitrification inhibitors, which first appeared in the increase of soil $\mathrm{NH}_{4}^{+}-\mathrm{N}$ content and the decrease of $\mathrm{NO}_{3}^{-}-\mathrm{N}$ content (Figure 1). The three nitrification inhibitors in this experiment can significantly slow down the conversion of ammonium to nitrate nitrogen in the early stage of culture. Maintaining higher levels of ammonium nitrogen in the soil for a longer period of time can, on the one hand, promote the absorption of ammonium by the crop, and on the other hand, the soil colloid can also fix a part of the ammonium nitrogen, thereby reducing the leaching of nitrate nitrogen. The results are the same as previous studies [23] [24]. During the cultivation period, soil pH and ammonium nitrogen were the same in all treatments, which was mainly related to the transformation of nitrogen in the soil. On the second day of culture, the $\mathrm{pH}$ of each treatment reached the highest value because urea was rapidly converted into ammonium nitrogen under suitable conditions after it was applied to the soil (Figure 2). In a short time, a large amount of ammonium nitrogen accumulated in the soil would inevitably result soil $\mathrm{pH}$ rise [25]. Subsequent nitri- 
fication results in oxidation of the soil's ammonium nitrogen to nitrate nitrogen, and $\mathrm{H}+$ released during this process lead to a drop in soil $\mathrm{pH}$ [26], but the CK treatment due to rapid nitrification has the largest drop in $\mathrm{pH}$ and has been at the lowest level. This result is similar to other literature reports [8] [25]. In this paper, the single applied urea-treated ammonium nitrogen reached the highest peak on the 2 - 4th day of culture, after which the soil ammonium nitrogen was converted to nitrate nitrogen by nitrification, and the ammonium nitrogen content decreased rapidly (Figure 1). In contrast, Nitrapyrin, DMPP, and DCD treatments maintained higher levels of ammonium nitrogen in the soil during early training, with a lower decrease. Nitrate nitrogen in the soil increased continuously during the whole cultivation process, contrary to the trend of ammonium nitrogen content, the nitrification inhibitor treatment of soil $\mathrm{NO}_{3}{ }^{-} \mathrm{N}$ content was lower than CK treatment, and continued until the end of the test culture, indicating that the inhibitory effect of nitrification inhibitors on the oxidation of $\mathrm{NH}_{4}^{+}$, this result is the same as previous research results [8] [27]. The nitrification inhibition rates of three nitrification inhibitors were $4.4 \%-48.5 \%$ (En), 6.7\% - 95.8\% (DMPP), and 5.1\% - 97.2\% (DCD), respectively, indicating that the inhibitory capacity of nitrification inhibitors was in the order of DCD > DMPP > En (Table 3 and Table 4), this result is contrary to previous research [9], which is due to the concentration of nitrification inhibitors. At the same time, the experiments showed that the inhibitory effect of DCD and DMPP was significantly higher than that of En $(\mathrm{p}<0.01)$. Due to the longer culture time between DCD and DMPP, the inhibitory effect of nitrification inhibitor gradually weakened in the later period and there was no significant difference.

\subsection{Effects of Nitrification Inhibitors on Nutrients in Soil and Citrus Seedlings}

The results of this study show that after 7 months of potted citrus planting, compared with the control, the three nitrification inhibitors can increase the plant height and dry matter accumulation of citrus seedlings, and promote the absorption and accumulation of nitrogen and phosphorus nutrients by citrus roots and leaves, but no difference in effect between the three nitrification inhibitors (Figure 3, Figure 4 and Table 5). At present, there are few reports on the application of nitrification inhibitors to the nutrient and dry matter accumulation of citrus seedlings, but there have been reports on other crops such as vegetables, and this result is similar to other literature reports [28] [29]. The reason why using nitrification inhibitors can increase the accumulation of nitrogen and phosphorus in seedlings may be that nitrification inhibitors can significantly inhibit denitrification and slow down the conversion of nitrogen from ammonium to nitrate in fertilizers. The presence of ammonium in the form of ammonium reduces nitrogen loss and increases nitrogen use efficiency [30]. Compared with urea alone (CK), applying nitrification inhibitors can increase the content of soil total nitrogen, alkaline nitrogen, ammonium nitrogen, and nitrate nitrogen content (Figure 6). This may be due to the conversion of most of ammonium 

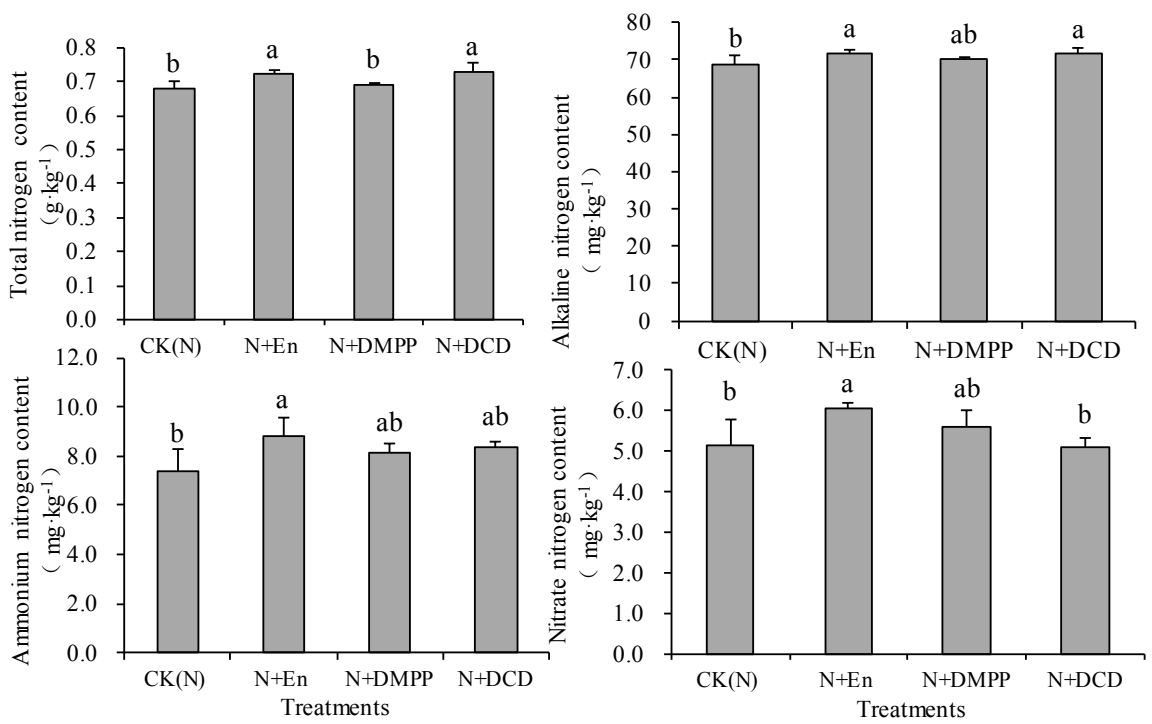

Figure 6. Effect of nitrification inhibitors on soil nitrogen.

nitrogen to nitrate-nitrogen in control resulting in the leaching of nitrogen from the soil, which increases the availability of nitrogen fertilizer [31]. Excessive application of nitrification inhibitors will have a toxic effect on crops, and different crops have different sensitivity to nitrification inhibitors [6].

\section{Conclusions}

1) The nitrification inhibitors DCD (dicyandiamide), DMPP (3,4-dimethylpyrazole phosphate) and Nitrapyrin (2-chloro-6-trichloromethyl pyridine) can reduce the conversion of ammonium-nitrogen to nitrate-nitrogen in soil, and slow down the nitrification rate and acidification rate of the soil. Under the experimental conditions and market recommended concentrations, the inhibitory ability of the three nitrification inhibitors was in the order of DCD > DMPP > En (based on nitrogen application). The inhibitory effect of DCD was slightly higher than that of DMPP, but they were significantly higher than En.

2) The application of nitrification inhibitors increased the plant height and dry matter accumulation of potted citrus seedlings, and the increase ranges were $7.6 \%-8.6 \%$ and $1.0 \%-3.8 \%$, respectively, and promoted the absorption and accumulation of nitrogen by citrus roots and leaves, which was respectively increased compared with the control treatment $9.0 \%-17.9 \%$ and $0.6 \%-7.2 \%$. At the same time, nitrification inhibitors can significantly increase soil total nitrogen, alkaline nitrogen content, compared with the control treatment, indicating improved nitrogen utilization.

\section{Acknowledgements}

This study was supported by the National Key Research and Development Project of China (No. 2016YFD0800304), the National Key Technology Research and Development Program (2015BAD06B04), the Fundamental Research Funds 
for the Central Universities (2362015xk06, XDJK2013C065 and 20710922).

\section{References}

[1] FAO. (2017) Statistics. http://www.fao.org

[2] Li, S.W. (2013) Study on the Nutrition Status and Variable Rate Fertilizer Practice to the Hill Orchards in the Three Gorge Area. Southwest University, Chongqing.

[3] Zhu, Z.L. (2008) Research on Soil Nitrogen in China. Acta Pedologica Sinica, 45, 778-783.

[4] Zhang, F.S., Chen, X.P. and Chen, Q. (2009) Guidelines for Fertilization of Major Crops in China. China Agricultural University Press, Beijing.

[5] Shen, Z.M. (2005) Advantages and Disadvantages of Citrus Industry Development in the Three Gorges Reservoir Area and Countermeasures. Citrus Fruit and Subtropical Fruit Information, 21, 10-12.

[6] Huang, Y.Z., Feng, Z.W., Wang, X.K. and Zhang, F.Z. (2002) Research Progress of Application of Nitrification Inhibitors in Agriculture. Chinese Journal of Soil Science, 33, 310-314.

[7] Singh, M., Pabbi, S., Bhattacharya, A.K. and Singh, A.K. (2007) Nitrite Accumulation in Coastal Clay Soil of India under Inadequate Subsurface Drainage. Agricultural Water Management, 91, 78-85. https://doi.org/10.1016/j.agwat.2007.04.010

[8] Shi, M., Liang, D.L., Man, L., Guo, L., Zhao, W.L. and Wang, C.H. (2012) Effects of Different Application Rates of DMPP and DCD on Nitrogen Transformation in Calcareous Soil. Scientia Agricultura Sinica, 22, 4635-4642.

[9] Wang, X.W., Liu, T. and Chu, G.X. (2017) Inhibition of DCD, DMPP and Nitrapyrin on Soil Nitrification and their Appropriate Use Dosage. Journal of Plant Nutrition and Fertilizer, 23, 54-61.

[10] Zhang, Z.C. (2017) The Mechanism by Which the Nitrification Inhibitor Nitrapyrin Affects the Fruit Quality of Korla Fragrant Pear (Pyrus bretschneideri Rehd.). Shihezi University, Xingjiang.

[11] Wang, Y.G., Meng, X.Y., Peng, S.M., Chu, G.X. and Liu, H.F. (2014) Effects of Nitrification Inhibitor Nitrapyrin $\left(\mathrm{N}^{+}\right)$on the Yield and Quality of Jujube (Ziziphus jujube Mill. Cv. Hui Zao). Xinjiang Agricultural Sciences, 51, 1803-1807.

[12] Wu, S.F., Wu, L.H., Yin, Y.M., Li, Q. and Yang, S.D. (2006) Effects of Compound Fertilizer with Nitrification Inhibitor on the Yield and Nutritional Quality of Watermelon and Cucumber. Journal of Agro-Environment Science, 25, 1432-1435.

[13] Cookson, W.R. and Cornforth, I.S. (2002) Dicyandiamide Slows Nitrification in Dairy Cattle Urine Patchs: Effects on Soil Solution Composition, Soil pH and Pasture Yield. Soil Biology and Biochemistry, 34, 1461-1465. https://doi.org/10.1016/S0038-0717(02)00090-1

[14] Du, L.L. (1994) Nitrification Inhibition of Dicyandiamide and Its Application. Progress in Soil Science, 22, 27-311.

[15] Molina, R.M. and Ortega, B.R. (2006) Evaluation of the Nitrification Inhibitor 3, 4-Dimethylpyrazole Phosphate in Two Chilean Soils. Journal of Plant Nutrition, 29,521-534. https://doi.org/10.1080/01904160500526584

[16] Pasda, G., Hähndel, R. and Zerulla, W. (2001) Effect of Fertilizers with the New Nitrification Inhibitor DMPP (3, 4-Dimeth-Ylpyrazole Phosphate) on Yield and Quality of Agricultural and Horticultural Crops. Biology and Fertility of Soils, 34, 85-97. https://doi.org/10.1007/s003740100381 
[17] Chuan, L.M., Zhao, T.K., An, Z.Z., Du, L.F. and Li, S.J. (2010) Effects of Adding a Nitrification Inhibitor Dicyandiamide (DCD) on the Growth and Quality of Rape. Journal of Agro-Environment Science, 29, 870-874.

[18] Yu, Q.G. and Chen, Y.X. (2011) Effect of the Urea with Nitrification Inhibitor DMPP Addition on Different Form Nitrogen Transformation in Rice Fields. Journal of Agro-Environment Science, 30, 1357-1363.

[19] Trenkel, M.E. (1997) Improving Fertilizer Use Efficiency Controlled-Release and Stabilized Fertilizers in Agriculture. International Fertilizer Industry Association, Paris, 53-102.

[20] Yang, J.H., Wang, C.L. and Dai, H. (2008) Soil Agrochemical Analysis and Environmental Monitoring. China Land Press, Beijing.

[21] Lin, J.H., Li, H.X., Hu, F. and Zhao, H.Y. (2004) Effect of Dry Soil Effect on Soil Biological Composition and Mineralization and Nitrification. Acta Pedologica Sinica, 41, 924-930.

[22] Mc, C.G.W. and Bremner, J.M. (1989) Inhibition of Nitrification in Soil by Heterocyclic Nitrogen Compounds. Biology and Fertility of Soils, 8, 204-211.

[23] Chaves, B., Opoku, A., De, N.S. and Hofman, G. (2006) Influence of DCD and DMPP on Soil N Dynamics after Incorporation of Vegetable Crop Residues. Biology and Fertility of Soils, 43, 62-68. https://doi.org/10.1007/s00374-005-0061-6

[24] Week, A., Benckiser, G., Herbert, T. and Ottow, I.C.G. (2001) Influence of the Nitrification Inhibitor 3,4-Dimethylpyrazole Phosphate (DMPP) in Comparison to Dicyandiamide (DCD) on Nitrous Oxide Emissions, Carbon Dioxide Fluxes and Methane Oxidation during 3 Years of Repeated Application in Field Experiments. Biology and Fertility of Soils, 34, 109-117. https://doi.org/10.1007/s003740100386

[25] Zhang, M.T. (2010) The Study of Inhibitory Effect and Mechanism of Different Nitrification Inhibitors in Calcareous Soil. Northwest Agriculture \& Forestry University, Shaanxi.

[26] Cabrera, M.L., Kissel, D.E. and Bock, B.R. (1991) Urea Hydrolysis in Soil: Effects of Urea Concentration and Soil PH. Soil Biology and Biochemistry, 23, 1121-1124. https://doi.org/10.1016/0038-0717(91)90023-D

[27] Zhang, M.T., Shi, M., Liang, D.L., Shen, F. and Dang, H.L. (2011) Effects of Different Nitrification Inhibitors on Urea Transformation. Journal of Northwest A\&F University (Social Science Edition), 39, 178-184.

[28] Yu, G.H., Zhang, Y.Z. and Wan, D.J. (2006) Effects of Nitrification Inhibitors on Nitrate Content in Soil and Pakchoi and on Pakchoi Yield. Chinese Journal of Applied Ecology, 17, 247-250.

[29] Xu, C., Wu, L.H., Zhang, L.M., Ju, X.T. and Zhang, F.S. (2005) Effect of Nitrogen Fertilizer with Nitrification Inhibitor DMPP on Nitrate Accumulation and Nutritional Quality of Brassica campestris L. Ssp. Chinensis. Plant Nutrition and Fertilizer Science, 11, 137-139.

[30] Magnard, D.N. (1978) Nitrate Environment. Soil-Plant-Nitrogen Relationship. Vol. 2, Academic Press, New York.

[31] Wu, S.F., Wu, L.H., Yin, Y.M., Yang, S.D., Chen, X.Y. (2007) Effects of DMPP-Compound Fertilizer on Greenhouse Celery Growth and Nutritional Quality. Chinese Journal of Applied Ecology, 18, 383-388. 